\title{
A CASE OF MALIGNANT HYPERPYREXIA THE DIFFICULTY OF DIAGNOSIS
}

\author{
MAJOR R. H. JAGO, M.A., M.B., B.Chir., F.F.A.R.C.S., R.A.M.C. \\ MAJOR M. J. PAYNE, M.B., B.S., F.R.C.S.(Ed.), R.A.M.C.
}

Cambridge Military Hospital, Aldershot

\begin{abstract}
SUMMARY: The history and management of a case of malignant hyperpyrexia is described. The difficulties associated with diagnosis are discussed, the variability of creatine phosphokinase (C.P.K.) values are again nóted, and the need for a high index of suspicion during any per-operative temperature rise is stressed.
\end{abstract}

\section{Introduction}

Malignant hyperpyrexia was first reported by Denborough (1962) as a potentially lethal, autosomal dominant syndrome of unknown aetiology. It may be triggered by most anaesthetic agents, but suxamethonium and halothane account for the majority of cases. Ellis (1973) described its outstanding features as a rapid rise of temperature in excess of $2^{\circ} \mathrm{C}$ per hour, tachycardia, tachypnoea and cyanosis. In addition Furniss (1971) noted that intense muscle rigidity developed in 75 per cent of cases and suggested that these were hereditary, whereas those in which rigidity was not a feature fell into a non-hereditary sporadic group. Isaacs and Barlow (1973) now dispute this suggestion, having identified cases of both types in the same family.

In 1970 Isaacs and Barlow noted a high resting serum creatine phosphokinase activity in affected members of the same family. They suggested that this indicated an underlying subclinical myopathy and could be used as a screening test for susceptibility to the syndrome. However Britt (1974) has reported other families with no clear cut C.P.K. elevations and noted that, in spite of meticulous sampling techniques, the reproducibility of C.P.K. values from day to day in the same susceptible patient is even poorer than in normal subjects.

This communication details a case of malignant hyperpyrexia in which diagnosis was initially not clear cut, but eventually made by a process of elimination.

\section{Case history}

A 25 year old soldier was admitted to hospital with a 36 hour history suggestive of acute appendicitis. He was heavily built, weighed $95.9 \mathrm{~kg}$, had had two previous general anaesthetics for menisectomy and tooth extraction, gave no history of adverse drug reaction, and was not taking any medication. Physical examination revealed guarding and rebound in the right iliac fossa, a positive psoas test, pulse rate of 104 , and an oral temperature of $37.2^{\circ} \mathrm{C}$. A diagnosis of acute retrocaecal appendicitis was made and the patient prepared for emergency surgery.

No premedication was given and following the establishment of an intravenous line with a 21 gauge butterfly needle general anaesthesia was induced using the following sequence : 
Atropine sulphate $0.6 \mathrm{mg}$, thiopentone sodium $500 \mathrm{mg}$, and suxamethonium chloride $75 \mathrm{mg}$ - this produced sleep and relaxation without undue muscle fasciculation. Intubation with an 11:0 cuffed oral Portex tube was achieved with ease, and the patient ventilated with nitrous oxide and oxygen ( $7: 3$ litres/minute) by means of an East-Radcliffe ventilator. The airway pressure registered $18 \mathrm{~cm} \mathrm{H}_{2} \mathrm{O}$, and a tidal volume of $950 \mathrm{ml}$ was delivered at a frequency of 12 per minute. When the patient started to show signs of movement $8 \mathrm{mg}$ of pancuronium bromide and $40 \mathrm{mg}$ of pethidine hydrochloride were administered and produced further good relaxation.

As the Surgeon was making the skin incision it was noted that the patient felt hot, was flushed, and had developed an irregular tachycardia of 160 per minute. An oesophageal thermistor was passed nasally and registered $39^{\circ} \mathrm{C}$. Ambient theatre temperature was $23.8^{\circ} \mathrm{C}$. The Surgeon was advised of the possible diagnosis of malignant hyperpyrexia and asked to terminate the operation as quickly as possible. An intravenous infusion of Hartmann's solution was established in the forearm and the $\mathrm{F}_{1} \mathrm{O}_{2}$ was increased to 40 per cent.

A gangrenous retrocaecal appendix was removed, the wound drained, and surgery completed in 15 minutes. While the peritoneum was open and the bowel in contact with moist saline packs and the atmosphere the oesophageal temperature fell to $37.5^{\circ} \mathrm{C}$.

Paralysis was reversed uneventfully with atropine $0.6 \mathrm{mg}$ and neostigmine 2.5 $\mathrm{mg}$, and the patient transferred to the Recovery Ward. A rectal thermistor was inserted and temperature recorded every 15 minutes. Cooling by means of an electric fan was instituted and infusion of Hartmann's solution continued. Despite these measures the rectal temperature continued to rise over the next 90 minutes (Fig. 1). This rise in excess of $40^{\circ} \mathrm{C}$ conforms with Frankel's (1972) definition of hyperpyrexia and the authors felt that it was most likely due to the malignant syndrome. However at this stage other causes, notably gram negative bacteraemia and drug induced fever, could not be excluded.

\section{Management}

Prior to any further therapy blood was taken for electrolytes, muscle enzymes, blood cultures, and arterial gases. More strenuous efforts at cooling were then instituted, the patient being packed in ice, fanned, and peripheral vasodilatation achieved using intravenous chlorpromazine $25 \mathrm{mg}$ two hourly. In addition specific therapy was commenced on the basis of the previously mentioned differential diagnosis. Intravenous solumedrone $500 \mathrm{mg}$ b.i.d. for 24 hours was given to abort malignant or drug induced hyperpyrexia, and continuous intravenous ampicillin two grams in 24 hours to counter a bacteraemic aetiology.

Over the next four hours the temperature returned to normal and thereafter the patient remained apyrexial and made an uneventful recovery. Active cooling was withdrawn, but specific therapy was continued as detailed and antibiotic cover maintained orally for 10 days.

Serial muscle enzymes were measured over the postoperative period and a deltoid muscle biopsy performed under procaine infiltration anaesthesia 11 days after surgery. Unfortunately neuropharmacological investigations are not available in our hospital. 

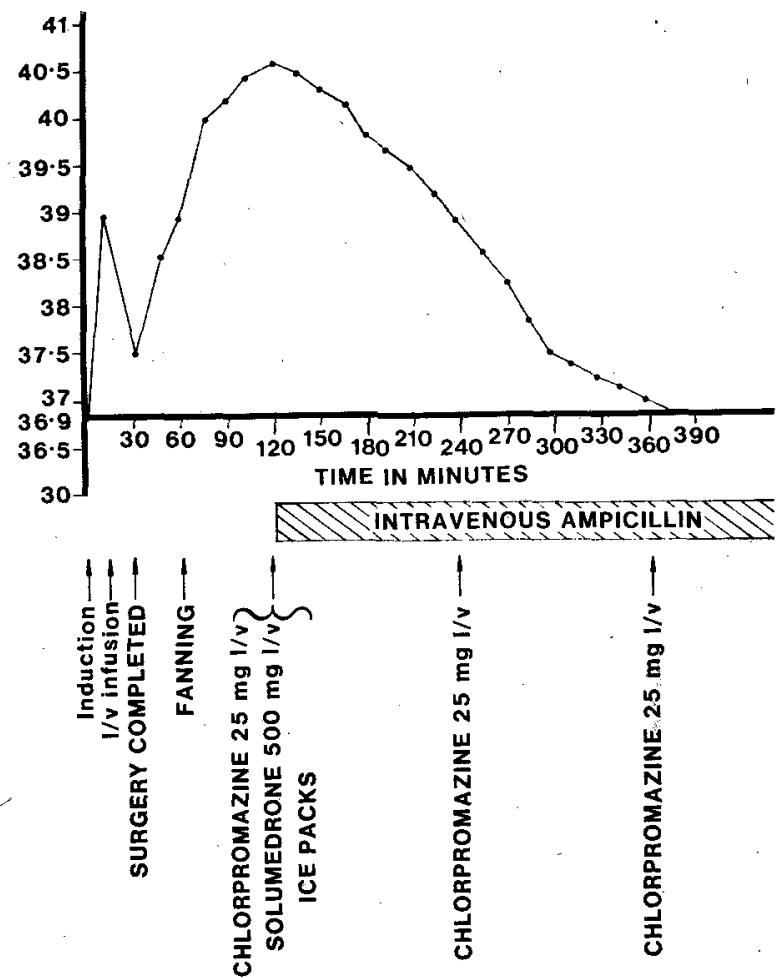

Fig. 1. Per- and postoperative temperature

\section{Results}

At the time of maximum fever the patient's blood pressure was $130 / 90 \mathrm{~mm} \mathrm{Hg}$ and heart rate 140 per minute. Blood $\mathrm{pH}$ was $7.33, \mathrm{Pac}_{\mathrm{co} 2}=39.1 \mathrm{~mm} \mathrm{Hg}, \mathrm{Pa}_{02}-56.3$ $\mathrm{mm} \mathrm{Hg}$, base excess $-0.2 \mathrm{mEq} / 1$, total $\mathrm{CO}_{2}=21.9 \mathrm{mEq} / 1$, serum $\mathrm{Na}^{+}=132$ $\mathrm{mEq} / 1, \mathrm{Cl}^{-}=95 \mathrm{mEq} / 1$, and $\mathrm{K}^{+}=3.9 \mathrm{mEq} / 1$. Three blood cultures failed to grow organisms.

On the first postoperative day haemoglobin was $14.5 \mathrm{~g} / 100 \mathrm{ml}$, P.C.V. $=41.6$ per cent, $\mathrm{WBC}=11,300 \mathrm{~mm}^{3}$, and E.S.R. $=12$ per cent.

Table I

Postoperative serum muscle enzyme activity

\begin{tabular}{|l|r|r|r|r|r|r|r|r|}
\hline & \multicolumn{7}{|c|}{ Days post-surgery } & Normal values \\
\cline { 2 - 6 } & 0 & 1 & 2 & 4 & 5 & 7 & 10 & \\
\hline $\begin{array}{c}\text { Creatine } \\
\text { phosphokinase }\end{array}$ & 206 & 898 & 842 & 346 & 185 & 51 & 59 & $36-188 \mathrm{Iu} / 1$ \\
\hline $\begin{array}{c}\text { Aspartate } \\
\text { transaminase }\end{array}$ & 21 & 32 & 65 & 50 & 39 & 23 & 27 & $10-30 \mathrm{Iu} / 1$ \\
\hline \begin{tabular}{l} 
Alanine transaminase \\
\hline $\begin{array}{c}\text { Lactate } \\
\text { dehydrogenase }\end{array}$
\end{tabular} & 28 & 32 & 75 & 84 & 71 & 54 & 69 & $6-37 \mathrm{Iu} / 1$ \\
\hline
\end{tabular}


Table I shows the serial changes observed in serum muscle enzyme activity during the postoperative period.

The deltoid muscle biopsy was reported as showing no histological abnormality and a full neurological examination of the patient revealed no clinically detectable underlying myopathy.

\section{Discussion}

The estimated incidence of malignant hyperpyrexia during anaesthesia is $1: 14,000$ in children, and $1: 40,000$ in a mixed hospital population (Snow, Healy and Vaughan 1972). Britt and Kallow (1970) estimate its overall mortality at 64 per cent, but state that cases recognised within 10 minutes of the onset of anaesthesia respond extremely well to treatment. Ideally susceptible individuals should be recognized pre-operatively, but it is important to maintain a high index of suspicion in any case of unexplained peroperative temperature rise.

What was the cause of the sudden rise in temperature in the case just reported?

At the time a bacteraemia was thought unlikely because the rise occurred prior to the opening of the peritoneum and manipulation of the bowel, and rose more rapidly and to a higher level than is usually associated with acute appendicitis. Britt, Webb and LeDuc (1974) report that fever secondary to infection usually subsides during anaesthesia since cessation of muscle activity and vasodilatation result in lowered heat production and accelerated heat loss. It was nevertheless thought necessary to cover the patient with antibiotics. Following therapy the temperature returned to normal within four hours and the patient remained apyrexial. Had infection been the cause a more gradual return with intermittent spiking would have been expected. Three clear blood cultures at the time of maximum fever, and a white count of only 11,300 one day postoperatively indicated that no bacteraemia of any significance had occurred.

The only drug used in the anaesthetic sequence associated with fever was atropine. It is known to cause a rise in temperature, a decrease in sweating, and an increase in heart rate. However Goodman and Gilman (1970) state that atropine induced hyperthermia is rarely a problem in adults, and only occurs if large doses in excess of $5 \mathrm{mg}$ are used in ambient temperatures greater than $27.5^{\circ} \mathrm{C}$. Clearly these criteria do not apply in this case.

Thus the Authors were left with a diagnosis of malignant hyperpyrexia. The patient had demonstrated definitive signs of the syndrome in that he suffered a rapid rise in temperature and irregular tachycardia following induction of anaesthesia. Hypoxaemia was observed, but the profound metabolic acidosis, hypercarbia, and hyperkalaemia often associated with the syndrome did not develop. Muscle rigidity was not specifically looked for per-operatively, but should have been noticed during laryngoscopy to pass the oesophageal thermistor, had it been present. Rigidity was not observed post-operatively. It could be that therapy aborted the syndrome before it developed or that the patient falls into the non-rigid category. 
Serial C.P.Ks were initially greatly elevated and might have been thought to clinch the diagnosis. However during the postoperative period they gradually returned to normal. Ellis et al (1975) have recently presented evidence challenging the validity of C.P.K. values in the screening of patients for susceptibility to malignant hyperpyrexia, having found widely differing values, at different times, in the same susceptible people. In addition Rosalki (1970) has enumerated a variety of other causes of elevated C.P.K., including exercise, injections, and surgery. The elevated values in this case might be ascribed to any or all of these causes.

Postoperatively some additional circumstantial evidence was elicited to support the diagnosis. The patient's father had had a problem while undergoing surgery several years previously and had been advised against having further general anaesthetics. Unfortunately it was impossible to obtain further details. No other member of his family has had problems with anaesthesia, but a brother, also serving in the Army, has elevated C.P.Ks and an abnormal muscle biopsy.

Clearly this patient does not entirely fit the classical picture of the syndrome, but he has suffered one attack of hyperpyrexia associated with anaesthesia, and this was successfully aborted following therapy along the lines recommended by Clark and Ellis (1974). The majority of cases previously reported have not occurred in patients undergoing surgery for conditions inherently associated with fever. This report details the problems of diagnosis when this occurs, and underlines the need for careful exclusion of other possible causes, as well as initiation of early active therapy.

\section{Acknowledgements}

The Authors wish to thank Colonel P. K. Coakley, L/R.A.M.C., for permission to report on his patient, and Dr. A. Barham Carter, Honorary Consultant Neurologist to the Army, for his assistance in neurological assessment of the case.

\section{REFERENCES}

Britt, B. A. and Kallow, W. (1970). Canad. Anaesth. Soc. J. 17, 293.

BrITt, B. A. (1974). New Engl. J. Med. 291, 1140.

Britt, B. A., Webi, G. E. and LeDuc, C. (1974). Canad. Anaesth. Soc. J. 21, 371.

Clark, I. M. C. and Ellis, F. R. (1974). Anaesthesia 29, 452.

Denborough, M. A., et al (1962). Brit. J. Anaesth. 34, 395.

ElLIS, F. R. (1973). Anaesthesia 28, 236.

Ellis, F. R., Clark, I. M. C., Modgill, M., Currie, S., and Harriman, D. G. F. (1975) Brit. med. J. iii, 511.

FranKel, R. J. (1972). Brit. J. Hosp. Med.8, 30.

Furniss, P. (1971). Proc. roy. Soc. Med. 64, 216.

Goodman, L. S. and Gilman, A. (1970). The Pharmacological Basis of Therapeutics. MacMil. lan Press. London.

IsAacs, H. and BarLow, M. B. (1970). Brit. J. Anaesth. 42, 1077.

ISAACs, H. and BARLow, M. B. (1973). J. Neurol. Neurosúrg. Psychiat. 36, 228.

Rosalki, S. B. (1970). J. clin. Path. 24 (Suppl.), 60.

Snow, J. C., Healey, G. B. and Vaughan, C. W. (1972). Arch. Otolaryng. 95, 442. 